\title{
A Concepção do Role-Playing Game (RPG) em Jogadores Sistemáticos
}

\author{
The Conception of the Role-Playing Game (RPG) \\ in Systematic Players \\ La Concepción del Role-Playing Game (RPG) \\ en Jugadores Sistemáticos
}

Ana Alayde Saldanha \& José Roniere Morais Batista

Universidade Federal da Paraíba

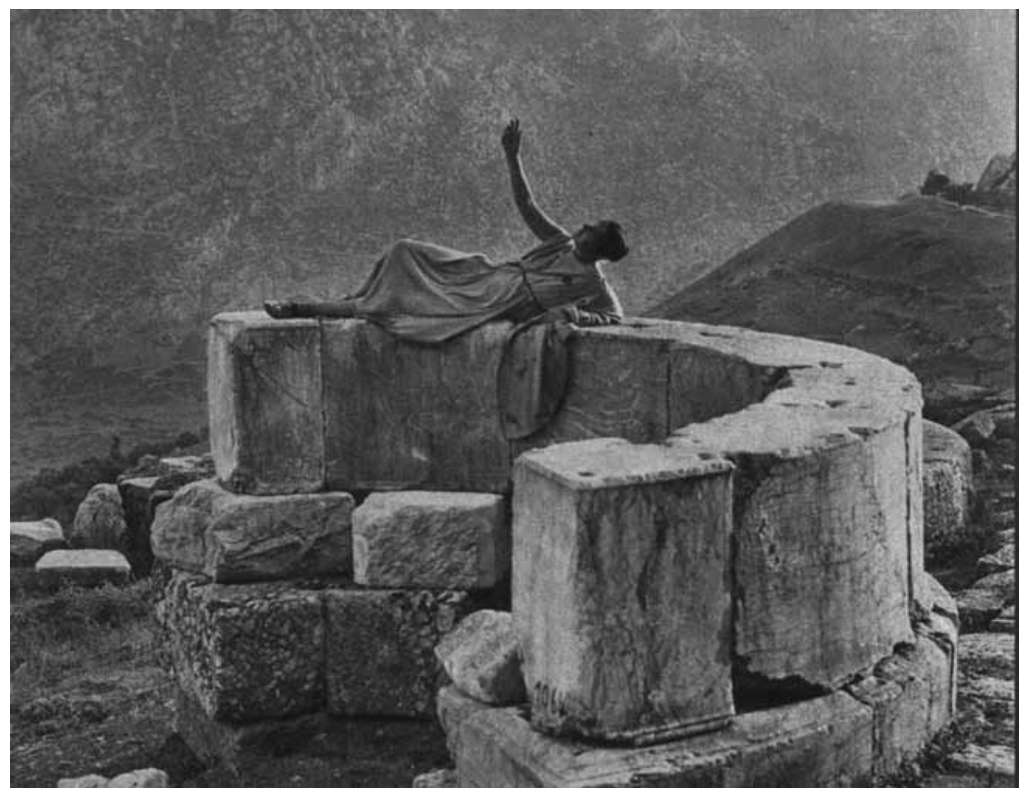


Resumo: O Role-Playing Game (RPG) vem ganhando cada vez mais espaço entre os jovens no Brasil e na área da pedagogia, na qual vem sendo utilizado como ferramenta de aprendizado nas salas de aula. Este trabalho teve como objetivo determinar qual a concepção que os jogadores sistemáticos possuem a respeito dos jogos de interpretação de personagens, ou Role-Playing Games, bem como quais os fatores motivacionais que levam à prática desse jogo. Foi utilizado para a coleta dos dados um questionário sociodemográfico e uma entrevista semi-aberta, sendo esta última analisada com base em categorias determinadas a partir dos temas suscitados. As categorias demonstraram que o RPG é percebido como um teatro improvisado, uma forma de lazer, uma terapia, uma projeção de personalidade, um facilitador das relações pessoais e como uma confraternização com amigos. Foi determinado ainda que o principal fator motivacional dos jogadores era a amizade, a vontade de estar com os companheiros de jogo. Aparentemente, o jogo de RPG possui tanto características positivas quanto negativas, sendo que a diferença estaria na forma como é utilizado. O resultado da pesquisa abre caminho para futuros estudos sobre esse tipo de jogo que já se encontra inserido na cultura em massa.

Palavras-chave: Role-Playing Game. Jogo. Jogos eletrônicos. Motivação.

Abstract: The Role-Playing Game (RPG) is becoming more and more usual among youths in Brazil and in the area of pedagogy, where it has been used as a learning device in classrooms. This work had as objective determine what is the conception that the systematic players possess regarding the games of characters' interpretation, or Role-Playing Games, as well as the motivational factors that lead to the practice of this game. It was used for the collection of the data a partner-demographic questionnaire and a semi-open interview; the last one was analyzed based on certain categories that started from the themes that were raised. The categories demonstrated that RPG is viewed as an improvised theater, a leisure activity, a therapy, a personality projection, a facilitator of personal relationships and as an opportunity to meet friends. It was certain that the players' main motivation was friendship, the will of being with the game companions. The game of RPG possesses positive characteristics as much as negatives, and the difference would be in the way it is used. The result of the research makes way for future studies on that kind of game that is already inserted in the mass culture.

Keywords: Role-Playing Game. Game. Electronic games. Motivation.

Resumen: El Role-Playing Game (RPG) viene ganando cada vez más espacio entre los jóvenes en Brasil y en el área de la pedagogía, en el cual viene siendo utilizado como herramienta de aprendizaje en las salas de clase. Este trabajo tuvo como objetivo determinar cual es la concepción que los jugadores sistemáticos poseen a respeto de los juegos de interpretación de personajes, o Role-Playing Games, así como cuales los factores motivadores que llevan a la práctica de este juego. Fue utilizado para la colecta de los datos un cuestionario sociodemográfico y una entrevista semi-abierta, siendo esta última analizada con base en categorías determinadas de los temas suscitados. Las categorías demostraron que el RPG es percibido cómo un teatro improvisado, una forma de ocio, una terapia, una proyección de personalidad, un facilitador de las relaciones personales y como una confraternización con amigos. Fue determinado todavía que el principal factor de motivación de los jugadores era la amistad, la voluntad de estar con los compañeros de juego. Aparentemente, el juego de RPG posee tanto características positivas como negativas, siendo que la diferencia estaría en la forma como es utilizado. El resultado de la pesquisa abre camino para futuros estudios sobre ese tipo de juego que ya se encuentra inserido en la cultura en masa.

Palabras clave: Role-Playing Game. Juego. Juegos electrónicos. Motivación.

A atividade lúdica está presente em todas as culturas do Planeta, ao longo da história da humanidade. Até mesmo os animais apresentam o comportamento de brincar, em que realizam uma simulação de luta, sem ferir o parceiro, em um ritual no qual respeitam a norma de não morder e até reconhecem a suposta vitória de um dos participantes. Huizinga (1996) acredita que é justamente essa peculiaridade do jogo, a de ocorrer tanto para os animais racionais como para os irracionais, que faz dele um fato mais antigo que a própria cultura, uma vez que esta última pressupõe a existência de uma sociedade humana. O jogo, ao contrário, vai ser encontrado como elemento antecedente à cultura, e vai acompanhá-la e marcá-la desde o início da sua formação até a nossa atual fase de civilização.

O autor aponta ainda algumas das características fundamentais do jogo, das 
Já existem

atividades no ambiente escolar em que os alunos são incentivados a interpretar, mas essas mesmas atividades não proporcionam a variedade de cenários e diálogos oferecidos pelo RPG, ficando restritas a eventos específicos (Silveira, n.d.) quais podemos citar: o fato de ser livre, de partir de uma atividade voluntária, de não ser visto como parte da vida real, mas justamente como uma evasão desta para uma esfera temporária com orientação própria, de ser isolado e limitado, jogado até o fim dentro de um segmento de tempo e espaço e por ser uma forma de ordem, possuindo ritmo e harmonia em regras que, quando não respeitadas, estragam o jogo (Huizinga, 1996). Para outros estudiosos, mais preocupados com a função do jogo, o ato de brincar desenvolveria a imaginação e a criatividade, beneficiaria a aquisição de leitura e escrita, a reflexão, a lógica e o raciocínio, além de contribuir para o desenvolvimento dos aspectos figurativos do pensamento (Fortuna, 2001).

O Role-Playing Game (RPG) surge, então, em um quadro em que o ato de jogar se encontra incluído na prática cotidiana de diversas sociedades nas mais variadas faixas etárias. E vai diferir de seus antecedentes por propor uma prática cooperativa e não competitiva entre seus participantes. Sua sigla vem do inglês e significa jogo de interpretação de papéis; foi criado nos Estados Unidos no ano 1975 e desenvolvido a partir de jogos estratégicos de guerra que simulavam batalhas em tabuleiros. De forma resumida, o jogo se baseia na premissa de que cada participante faz o papel de um personagem em uma aventura imaginária. Essa aventura é narrada por um árbitro normalmente chamado de Mestre, que, por sua vez, descreve tudo o que ocorre nos cenários, como o que os jogadores vêem, ouvem, sentem, etc. Os jogadores, em seguida, descrevem o que seus personagens fazem frente à situação proposta, o Mestre narra o resultado das ações dos personagens, e assim sucessivamente (Jackson, 1994). O funcionamento é similar a um teatro, só que aqui a peça vai sendo escrita na medida em que acontece, e cada personagem define o próprio roteiro e todos os personagens coadjuvantes são interpretados pelo Mestre. Cada jogador pode criar sua personagem seguindo uma limitação proposta pelo sistema de RPG em uso.

Esse jogo de interpretação vem ganhando espaço no campo da pedagogia, sendo cada vez mais utilizado em salas de aulas e em oficinas com o objetivo de promover novas técnicas de ensino. Devido ao seu caráter lúdico e à sua inserção no contexto de cultura em massa, o RPG promoveria uma conduta mais ativa e dinâmica entre os alunos (Klimick \& Bettocchi, 2003; Rodrigues, 2004; Silveira, n.d.). Já existem atividades no ambiente escolar em que os alunos são incentivados a interpretar, mas essas mesmas atividades não proporcionam a variedade de cenários e diálogos oferecidos pelo RPG, ficando restritas a eventos específicos (Silveira, n.d.)

Rodrigues defende o uso do RPG como ferramenta para a aplicação da pedagogia da imaginação proposta por Ítalo Calvino. Apresenta em seu trabalho sugestões de como orientar professores e alunos no caminho de uma invenção do real, da ficção, que auxiliaria no desenvolvimento dos hábitos de leitura e escrita. Destaca três passos fundamentais para que um ser humano saudável e letrado escreva. O primeiro deles é um acervo básico, uma base de histórias, um conjunto de exemplos que sirvam para estabelecer um modelo de narrativa. O segundo é uma platéia inicial sensibilizada ${ }_{\llcorner}$é o desenvolvimento de um clima para compartilhar o que foi produzido pelo aprendiz em uma platéia generosa e honesta, que saiba aplaudir, criticar e debater as histórias. O último passo, e o mais trabalhoso, consiste em uma iniciação competente, ou seja, na orientação do aprendiz por uma pessoa capacitada para entender o funcionamento da máquina narrativa. Para pôr em prática seu trabalho, Rodrigues desenvolveu, nos moldes do RPG, o jogo autoria, que vem aplicando em sala de aula desde 1998 (Rodrigues, 2004). 
A idéia de que a prática da narrativa auxiliaria no desenvolvimento da escrita também foi apresentada por Simões (2000). A autora indica uma diferença entre as histórias contadas e lidas, em que, nas segundas, a criança aprenderia por experiência a estrutura da história, da linguagem e o som de um texto escrito lido em voz alta. Apesar do trabalho de Simões ser direcionado para as crianças e ser centrado nas histórias infantis, não deve ser descartada a necessidade de se verificar a relação da narrativa com o aprimoramento da escrita em adolescentes, e até mesmo em adultos. Essa conduta levaria ao processo de criação da linguagem, evitando o posicionamento passivo dos estudantes frente à educação. Uma das suas propostas apresentadas para os professores envolveria, assim como nos jogos de representação, a oralidade e a dramatização:

O educador poderia solicitar, por exemplo, que a criança reproduza oralmente as narrativas lidas por ele. Nesse sentido, seria interessante também estimular que a criança "leia" as histórias (leitura de faz-deconta) para seus colegas. Essas atividades de retomada da história poderiam ir se desdobrando, por sua vez, em outras, como desenho, dramatizações, etc. (Simões, 2000, p. 27)

A característica atuante do RPG seria, dessa forma, um dos seus principais destaques, uma vez que ele permitiria a oportunidade de fugir da narrativa tradicional, oferecendo uma base sobre a qual os jogadores construissem coletivamente suas próprias histórias (Klimick \& Bettocchi, 2003). A esse tecer de histórias e imagens feito pelos participantes, que retiram sua matéria-prima de outras fontes, gerando uma linguagem que reinterpreta a narrativa, Mota (como citado por Pavão, 1999) chama de pilhagem narrativa. Essa pilhagem, no entanto, não seria um mero processo de repetição, mas uma atividade atualizante, já que permite o processo de criação. Para defender essa idéia, Klimick e Bettocchi usam a teoria de Pierre Lévy, na qual é feita uma distinção entre as dicotomias do possível-real e do virtual-atual. Na transição do possível para o real, não haveria processo de criação, eles seriam iguais, sendo que o primeiro não tem a existência. "É como quando digitamos a tecla a no teclado do computador e na tela aparece a letra a. Não há surpresa, não há criação" (p. 6). Já no processo do virtual para o atual, acontece a resposta para um problema, como ocorre, seguindo o exemplo anterior, na escolha do texto a ser digitado.

Não estamos aqui escolhendo dentre um grande número de possibilidades prédefinidas o texto que vamos escrever, isso seria ir do possível para o real; estamos indo de um número teoricamente infinito de textos possíveis para aquele que julgamos ser a solução do problema, criando autonomamente, indo do virtual para o atual. (Klimick \& Bettocchi, 2003, p. 7)

Os autores concluem que:

Quando um grupo de jogadores escolhe um cenário de RPG, cria suas personagens e joga uma história, e, mesmo que essa seja uma "aventura-pronta" publicada por uma editora, a passagem é do virtual para o atual, e não do possível para o real. (p. 7)

Os RPGs não se limitam apenas aos jogos de tabuleiro, sendo muito difundidos no mundo dos jogos eletrônicos, onde são conhecidos como MMORPG (Massive Multiplayer Online Role-Playing Games). Aqui os participantes se conectam em servidores da internet e interagem com outros jogadores no mundo inteiro. Um dos MMORPG mais populares é o World of Warcraft (WoW), que conta hoje com mais de oito milhões de assinantes.

É importante ressaltar que existem diferenças nessas modalidades de jogo. O RPG tradicional requer a presença dos participantes em um ambiente físico, real, e a interação aqui é feita com os jogadores. Já no MMORPG, o contato é completamente feito no campo 
virtual, o que leva ao isolamento físico dos jogadores, sendo a interação aqui feita com os personagens. Esse tipo de isolamento causa polêmica, principalmente depois que cientistas reunidos em um congresso de games em Ultrecht (Holanda) afirmaram que o videogame causa tanta dependência como outras drogas (Games, 2003). As pesquisas nessa área têm aumentado após a divulgação de casos em que jovens morreram depois de horas de jogo no computador. Um desses exemplos é a de uma menina de Pequim, que possuía o nickname de Snowly, e que faleceu após jogar por vários dias consecutivos o WoW. Uma semana após o seu falecimento, seus amigos online realizaram um funeral virtual para Snowly (Ivanov, 2005).

Os problemas citados acima para os RPGs online, no entanto, não fazem com que a modalidade tradicional do jogo fique isenta de críticas. O assassinato de duas adolescentes em Teresópolis, Rio de Janeiro, em 2000, e outro assassinato em Ouro Preto, no interior de Minas Gerais, no ano 2001, foram associados ao jogo de RPG Vampiro - A Máscara. Os suspeitos teriam, segundo a polícia, reproduzido os rituais do jogo que resultaram na morte das vítimas (Lopes, 2003). Outro caso ocorreu em 2005, quando dois jovens (22 e 21 anos) mataram um colega de jogo e seus pais, durante uma sessão de RPG. O jovem que era o Mestre da partida afirmou em seu depoimento que o jogo havia tomado a sua cabeça de forma muito maligna. O que permanece indeterminado nesses casos é se os jovens já possuíam a personalidade anti-social antes de praticarem o jogo ou se o último contribuiu para a estruturação da mesma.

Diante dos fatos citados anteriormente e do número cada vez crescente de jovens que aderem à prática do RPG, fica clara a importância de se investigar mais de perto como esse jogo se relaciona com seus jogadores bem como de definir o perfil que estes possuem. O número ainda pequeno de material publicado sobre esse tema, e muito limitado à área da pedagogia, só ressalta mais a necessidade de explorá-lo de forma mais detalhada. Partindo desses pressupostos, o presente estudo teve como objetivo verificar a concepção do jogo de Role-Playing Game em jogadores sistemáticos. Para tanto, procurou descrever o perfil dos jogadores de RPG, identificar o significado do RPG para esses jogadores e determinar a motivação que leva à prática do RPG.

\section{Método}

A amostra foi delimitada por critério de saturação, e consistiu de 9 jogadores que praticam o RPG há mais de um ano, entre a faixa etária de 20 a 25 anos (idade média de 22,9), e que realizam sessões de jogo pelo menos uma vez por mês.

Os instrumentos utilizados foram um questionário sociodemográfico e uma entrevista semi-estruturada, que foram aplicados a cada participante individualmente. O primeiro teve por finalidade caracterizar os participantes, com questões que versaram sobre: idade, sexo, estado civil, profissão, grau de escolaridade, tempo de jogo, freqüência de jogo, prática de outras modalidades de RPG, duração da sessão de jogo e religião. A entrevista teve por objetivo explorar a relação dos jogadores com o RPG com questões sobre significado do jogo, motivação, aspectos positivos e negativos e relevância do jogo em sua vida.

Cada participante, ao ser contatado, foi informado acerca do estudo bem como acerca do caráter voluntário da sua participação. Em seguida, foi solicitado a responder, individualmente, os dados sociodemográficos e a entrevista semi-aberta, que teve suas informações transcritas para análise. 
Os dados sociodemográficos foram analisados através de estatística descritiva, com a utilização de medidas de posição (média, mediana) e de variabilidade (desvio padrão, amplitude). A análise dos conteúdos das entrevistas foi realizada com base em categorias determinadas a partir dos temas suscitados nas entrevistas e processada em uma série de etapas, de acordo com a proposta de Figueiredo (1993).

O projeto foi submetido e aprovado pelo Comitê de Ética em Pesquisa, do Centro de Ciências da Saúde (CCS) da Universidade Federal da Paraíba (UFPB), sendo seguidos todos os procedimentos para pesquisa com seres humanos do Ministério da Saúde (Resolução no 196/96).

\section{Resultados}

\section{Perfil dos participantes}

A maioria dos participantes entrevistados é do sexo masculino $(\mathrm{N}=7)$, fato também evidenciado no discurso das entrevistas, nas quais se aponta a idéia de que o jogo de RPG é predominantemente praticado por homens. A faixa etária dos participantes variou entre 20 e 25 anos (média de 22, 9), sendo que as maiores freqüência encontradas foram justamente os extremos dessa variação (20 e 25 anos), ambas com 33,3\% de ocorrência. Quanto ao tempo em que jogam RPG, obteve-se uma variação que vai de 5 a 17 anos, com a média de 10,6 anos, sendo que a maioria deles $(\mathrm{N}=6)$ joga há mais de 10,5 anos.

Neste ponto, deve-se ressaltar uma conseqüência resultante dessa variação na idade dos jogadores. O jogo de RPG começou a se popularizar no Brasil no início da década de 90, e, como a maior parte dos entrevistados possuía mais de 23 anos, acompanharam de perto esse fenômeno.
Como conseqüência, eles se consideram precursores do movimento do jogo no Brasil e se diferenciam da nova geração de jogadores, que, segundo eles, não sabem realmente reconhecer o verdadeiro fundamento do jogo (que estaria na capacidade de interpretação dos personagens). Segundo o relato de jogadores mais experientes feitos em momentos que intercalavam as entrevistas, e nos momentos nos quais foram estabelecidos os contatos iniciais, denominavam o grupo que acompanhou a chegada do RPG de geração xerox, pois, como os livros que continham as regras do jogo eram muito caros, faziam fotocópias do original. E chamam o grupo de novatos de roladores de dados, pois afirmam que estes estão mais preocupados com o sistema de combate do jogo, em vez de se concentrarem na interpretação dos personagens.

No que se refere ao sistema de jogo adotado pelos participantes, apenas dois foram mencionados, o Advanced Dungeons and Dragons (Winter, 1999) e o Dungeons e Dragons (Cook, Twet, \& Williams, 2004). Na verdade, esses dois jogos fazem parte do mesmo sistema de RPG, diferenciando-se um do outro apenas pela edição, que nada mais é que uma atualização das regras. Essa ocorrência pode ser explicada pelo fato de que uma das estratégias utilizadas para se estabelecer contato com a amostra foi a de pedir para o entrevistando indicar o nome de outros dois jogadores para a entrevista. Como cada grupo de RPG mantém uma relação com os seus integrantes e com outros grupos que jogam o mesmo sistema, pode-se esperar que os nomes indicados pelo entrevistando fizessem parte desse meio social.

Apenas um dos entrevistados era casado, e nenhum deles possuía filhos. Em relação à profissão, mais da metade $(\mathrm{N}=6)$ eram estudantes. Na escolaridade, todos os entrevistados tinham o segundo grau 
completo, dos quais três haviam concluído o ensino superior. Seria preciso realizar uma coleta em grande escala para verificar se esse padrão se repete, já que assumimos que, para se jogar RPG, é preciso ter conhecimento de livros de regras extensos e com conteúdos que requerem certa habilidade matemática.

A freqüência em que jogavam RPG variou de uma vez por mês até quatro vezes por mês (divididas em uma sessão por semana). E a duração de cada sessão de jogo era de 4 a 7 horas, sendo a média de 5 horas.

Dos participantes entrevistados, quatro não possuíam religião, e, dos três que faziam parte da religião católica, apenas um afirmava ser praticante do culto religioso. Os outros participantes afirmaram ter crenças em outras formas de manifestação religiosa ou espiritual. Como exemplo desse tipo de resposta, obteve-se: "Todas e nenhuma", ou "Digamos que nenhuma... Acredito que isso não seja necessário para alcançar ou louvar o que chamamos de Deus. Ateu não, porque eu acredito em Deus ou algo similar..." Esse resultado chama a atenção para o fato de que a quase totalidade desses jogadores não possui religião ou não tem uma posição definida em relação a ela.

Quase a metade dos entrevistados $(\mathrm{N}=4)$ pratica algum tipo de RPG online, ou MMORPG, e esse mesmo número jogou (ou ainda joga) outros sistemas de RPG, além dos que praticam com freqüência determinada. Um dos entrevistados é Mestre nos jogos de RPG, quatro participam como jogadores e os quatro restantes em ambas as posições (como jogadores em um grupo e Mestres em outros, nunca os dois no mesmo grupo).

\section{Entrevistas}

A partir da análise do discurso dos participantes, emergiram cinco categorias temáticas: conceito do RPG, motivação para o jogo, aspectos positivos, aspectos negativos e atitude defensiva.

A primeira das categorias apresentada, conceito de RPG, que indica a forma como esses jogadores percebem e definem esse tipo de jogo, ficou subdividida em seis subcategorias denominadas respectivamente: RPG como teatro, facilitador das relações sociais, forma de lazer, terapêutico, projeção de personalidade e confraternização com amigos, conforme pode ser observado na Tabela 1. Na primeira das subcategorias, RPG como teatro, verifica-se que a definição desse jogo é a de um teatro interativo, como um filme que vai sendo interpretado de forma dinâmica, no qual são usados apenas os elementos verbais e oriundos da imaginação. Abrange o aspecto principal do jogo de RPG, que é a interpretação de papéis, e é justamente a idéia inicial passada nos capítulos introdutórios dos livros de regras (Jackson, 1994). Essa subcategoria, em conseqüência, contém as maiores freqüências de respostas. A subcategoria seguinte é a de facilitador das relações sociais, e traz a idéia de que o RPG auxiliaria na aquisição de novas amizades, atuando como ferramenta que aproxima pessoas e grupos, característica essa que vai ser, em seguida, apontada por alguns participantes como um fator positivo do RPG. A terceira sub-categoria, forma de lazer, assume a dimensão lúdica do RPG, considerando-o uma alternativa de diversão. A subcategoria terapêutico vai ser a que atribui características terapêuticas ao jogo, afirmando que nele é possível deixar os problemas de lado e de expressar o mundo interior de cada jogador. As duas últimas subcategorias são a projeção de personalidade, que coloca o RPG como espaço que permite ao jogador se projetar, e confraternização com amigos, que remete à amizade formada no grupo de jogo, tema retomado posteriormente nos fatores motivacionais, nos aspectos positivos do jogo 
e no primeiro contato com o mesmo. A Tabela seguinte traz as evocações ligadas à formação dessas subcategorias.

Tabela 1. Dados referentes à categoria conceito de RPG.

Subcategoria Exemplos das Evocações

RPG como "Seria mais ou menos como teatro sem o script" (entrevistado 01).

teatro

"Uma espécie de teatro..." (entrevistado 07).

"Bom, acho isso... é um teatro que você não precisa atuar com movimentos, apenas argumentos e imaginação" (entrevistado 07).

"Significa uma espécie de filme que você dirige, e os atores são os meus amigos, em um mundo nosso, onde as leis universais somos nós que criamos... ahn... Algo próximo a um teatro improvisado..." (entrevistado 08).

Facilitador das

"É um estilo de vida, eu poderia dizer, porque... o RPG ele promove, assim, relações sociais uma interação social diferente de qualquer outra coisa que eu já tenha experimentado na vida né?(...)" (entrevistado 02).

"É um momento de diversão, de lazer, e principalmente de companheirismo..."

Forma de (entrevistado 03).

lazer

“...O RPG pra mim é mais diversão, é sair da rotina e é o que todo mundo deveria fazer, ou faz, de uma certa forma. Com esporte, com passeio, com lazer, pra mim é uma forma de lazer" (entrevistado 04).

Terapêutico

"Pra mim, eu acho que é como uma terapia. Minha válvula de escape, tipo assim, esquecer os meus problemas, que eu acho que é pra todo mundo né? (...)" (entrevistado 05).

"Pode ser definido pra mim como uma forma de escape do mundo real, ou até uma forma de expressar um pouco do meu mundo interior para os ouvintes..." (entrevistado 02).

Projeção de

No personagem, eu tive a liberdade de me projetar sem... achando que não personalidade estaria sendo reconhecido, mas, no final das contas, eu notei que eu era justamente o que tinha interpretado. Então eu acho que o PRG é um jogo de projeção de personalidade" (entrevistado 06).

Confraternização com amigos

"Significa encontrar com amigos e jogar conversa fora durante algumas horas" (entrevistado 09).

A segunda categoria emergente foi a motivação para o jogo. Essa categoria foi evocada principalmente nas respostas à pergunta "o que o levou a jogar?", que tinha por principal objetivo 
determinar quais os motivos iniciais para o ingresso nesse tipo de jogo. A motivação inicial para o RPG, objetivo primeiro do questionamento, acabou sendo apontada pelos participantes como a_curiosidade de saber sobre esse tipo diferente de jogo.

O primeiro contato que tiveram com o RPG foi relatado de quatro formas diferentes: através de amigos (maior incidência), através dos próprios livros de RPG, através de revistas especializadas no tema e através de professores. Essa freqüência de respostas era esperada, visto que, como já mencionado anteriormente, a maior parte dos entrevistados participou do surgimento do jogo no Brasil, além da escassez de material em português e do alto custo dos livros que favoreceram a divulgação do jogo pelo contato pessoal, feito entre amigos. O relato do entrevistado 03, que teve conhecimento do jogo através do seu professor de línguas, corrobora essa idéia. O professor que introduziu o jogo aos alunos o conheceu quando viajou para os Estados Unidos, onde o RPG era jogado desde a década de 80.

Quando questionados sobre o que os levava a continuar a jogar, com exceção de apenas um participante, todos os demais que responderam afirmaram que o fator motivacional era a amizade, a relação com os integrantes do grupo. O participante que respondeu de forma diferenciada apontou como fator motivacional a possibilidade de fazer o personagem se desenvolver, de obter poder para destruir obstáculos maiores. Podemos verificar neste último uma força motivacional intrínseca, ligada a elementos do jogo, enquanto, para os demais, a força motivacional é extrínseca ao jogo, vem dos integrantes que constituem o grupo, da interação estabelecida com eles, sendo a temática da amizade um fator recorrente em várias entrevistas e apontada como um dos aspectos positivos do RPG.

Outra dimensão importante trazida pelas entrevistas é a dificuldade pelas quais os jogadores passaram (ou passam) na vida: dos nove entrevistados, por exemplo, três possuem pais divorciados e um havia perdido um irmão. E, no relato de alguns deles, foi posta em questão a idéia de que, por considerarem o RPG uma maneira de "sair da realidade", seria comum sua prática por jovens com problemas: "A maioria do povo que joga RPG que eu vejo, tem problemas em casa, tem problemas..." (entrevistado 01). Ou ainda: "...É tipo um ópio, você esquece o mundo real e vai pro mundo imaginário. Você foge um pouco dos seus problemas, das suas raivas" (entrevistado 01). "Pra mim, eu acho que é como uma terapia, minha válvula de escape, tipo assim, esquecer os meus problemas, que eu acho que é pra todo mundo, né? (...)" (entrevistado 05). Entretanto, é necessária uma coleta em uma amostra representativa dessa população para que se possam verificar tais afirmações.

As categorias seguintes dizem respeito aos aspectos positivos e negativos do jogo de RPG apontados pelos entrevistados. A Tabela 2 traz alguns exemplos das evocações para a categoria aspectos positivos:

Tabela 2. Dados referentes à categoria aspectos positivos do RPG.

Subcategoria

Aumento de raciocínio
Exemplos das Evocações

"Bom, eu não tenho dúvidas de que o raciocínio da pessoa melhora muito..." (entrevistado 01).

"...Eu acho que é justamente isso, a parte que o Mestre... tanto o Mestre, porque é difícil fazer uma aventura bem bolada, com os desafios, tanto os jogadores que tem que passar pelos desafios do Mestre. E isso quer queira, quer não, a pessoa tá raciocinando, se esforçando, tipo um xadrez. ..." (entrevistado 01). 
Aumento de raciocínio
"...Ah! Tem uma coisa bem interessante, o RPG, ele ajuda muito você na questão do raciocínio..." (entrevistado 02).

“...Num gostava muito de matemática, aí, depois que eu comecei a jogar, um sistema chamado GURPS, e ele tem muito aquela questão de distribuir pontos, você tem que fazer muito cálculo pra fazer o personagem..." (entrevistado 02).

“...Eu tenho um pensamento matemático legal, e GURPS precisa de um pensamento matemático mais apurados do que os outros RPGs" (entrevistado 03).

"Eu acho que uma terceira foi minha capacidade de raciocínio, que aumentou, né?" (entrevistado 04).

"E a questão de raciocínio rápido, que eu acho ótimo assim. Você tem que pensar. Acaba aprendendo, mesmo que você não goste, você acaba aprendendo a raciocinar sob pressão" (entrevistado 05).

"E também tá relacionado a raciocínio quando, por exemplo, temos que resolver enigmas" (entrevistado 07).

“...Desenvolve bastante a capacidade de pensamento abstrato, desenvolve o raciocínio lógico e estratégico..." (entrevistado 08).

"...Porque tem gente que num jogava RPG que eu conheci, que era tímido, calado, aí começou a jogar, e, depois de ano, já é outra pessoa ..." (entrevistado 01).

Diminuição da timidez

“...Eu penso assim, a maioria do povo de RPG deve pensar a mesma coisa, porque... desinibe a pessoa, desinibe muito..." (entrevistado 01).

"...Humm, me trouxe um pouco de trato social, por assim dizer, porque quando eu era mais novo, eu era mais tímido, bem mais tímido. E depois que eu comecei a jogar o RPG, eu fiquei bem mais desinibido" (entrevistado 02).

"Bom... Alivia muito o estresse. Alivia muito o estresse, desfaz aquele problema na cabeça que você não consegue tirar..." (entrevistado 01).

“...O RPG é meio que como uma válvula de escape desse estresse que a gente

Função de tem no dia a dia..." (entrevistado 02).

catarse

“...E então eu acabava, mesmo sem quebrar o pau, eu acabava botando pra fora no jogo e aí em casa, eu tava conseguindo ficar mais tranqüila. Conversava, tentava ir conversar, falar o que eu tava sentindo antes de brigar..." (entrevistado 05).

“...O RPG é uma forma de sair um pouco da realidade meio cruel desse mundo, nos dá a possibilidade de nos aventurarmos em nossos próprios pensamentos, histórias e imaginação..." (entrevistado 02). 
Prevenção

contra drogas
"Bom, uma coisa muito positiva que eu acho do RPG, é porque a maioria das pessoas que jogam RPG não usam drogas..." (entrevistado 01).

“...Tanto que todos os grupos que eu jogo, somando, dá umas 25 pessoas. Das 25, três bebem. O resto não bebe..."(entrevistado 01).

"Eu acho que o principal do... a melhor coisa que o RPG traz é essa questão da interação social, porque você forma um grupo de amigos forte que tá.... preso por um elo em comum, que é o RPG..." (entrevistado 02).

"...Me socializar, acabei conhecendo muita gente por causa do RPG ..." (entrevistado 03).

"Como quarto benefício que me trouxe é que, acho sempre bom conhecer

Promove a interação social gente nova, e o RPG proporciona isso..." (entrevistado 04).

"Acho que uma das coisas positivas foi amigos, assim, que ficaram mesmo, né? (...)" (entrevistado 05).

“...Possibilita reunir os amigos em um final de tarde de domingo monótono e pôr a conversa em dia" (entrevistado 08).

"Fez com que eu conhecesse muita gente" (entrevistado 09).

Incentivo à

aquisição

"Inglês. Eu comecei a me dedicar ao inglês depois que comecei a jogar RPG, porque, na época que comecei a jogar, todos os livros que existiam no Brasil eram em inglês..." (entrevistado 02).

de novos idiomas

“... Eu aprendi a falar inglês por causa do RPG, não só RPG de mesa, mas RPG de videogame também..." (entrevistado 03).

“...No RPG, eu posso ser o cowboy, o astronauta, o gladiador, e me divertir no processo" (entrevistado 02).

Vivenciar diferentes experiências

"...É você conseguir se colocar em situações diferentes e imaginar como seria você sendo uma pessoa diferente. Como seria se eu fosse uma mulher, por exemplo..." (entrevistado 03).

"Uma coisa que eu vejo de bom é a possibilidade da pessoa... de você realizar, de você vivenciar, de ter experiências que você não pode ter na vida real" (entrevistado 06).

"...Pra quem lê os livros de RPG, por exemplo, Vampiro, ele sugere livros pra

Contato com você ler, porque têm temas parecidos. Qualquer RPG sugere vários... pra D\&D ele sugere Excalibur..." (entrevistado 03).

outras formas de cultura

“...Então você vai atrás de referências históricas, referências bibliográficas e geográficas. Você vai atrás de mitos, lendas, e até mesmo cálculos matemáticos, pra poder entender determinadas mecânicas de jogo, de sistemas. Como também noções de Física e biologia, e por aí vai..." (entrevistado 04).

"Ler também, cotidianamente, já que você se envolve com história e como todo romance são histórias também, você acaba lendo" (entrevistado 03).

Incentivo à

leitura

"A segunda coisa, pra mim, que me trouxe, foi o incentivo à leitura, porque eu infelizmente só vim tomar gosto por leitura aos dezoito anos" (entrevistado 04). 
continuação da tabela 2

Estimula

a imaginação
"Outra característica positiva do RPG é a imaginação, você desenvolve muito a sua imaginação" (entrevistado 03).

"A primeira coisa que o jogo traz de positivo, pra mim, é criatividade..." (entrevistado 04).

Estimula

a criatividade
"...Eu comecei a usar mais a minha criatividade, que eu achava que não tinha..." (entrevistado 05).

“...Tem também a fantasia, o fato de você encarnar um personagem estimula a criatividade" (entrevistado 07).

Em relação à categoria aspectos positivos, a subcategoria com maior freqüência de respostas foi a de aumento de raciocínio (sete dos nove entrevistados apontaram essa característica). Os manuais dos jogos de RPG são repletos de tabelas e cálculos necessários para a construção dos personagens, criação dos cenários, regras de combate, movimentações nos mapas e para determinar a probabilidade de diversas ações do jogo. Alguns jogadores acreditam que, por terem que assimilar tais regras e por praticá-las nas sessões, acabariam por desenvolver sua capacidade de raciocínio. Apontam também o fato de que as situações-problema propostas pelo Mestre exigem soluções rápidas e criativas. É importante ressaltar que nem todos os jogadores possuem o mesmo desempenho no ambiente de jogo, e é comum encontrar pessoas que jogam há muito tempo, mas que não dominam as regras, que acabam ficam a cargo dos colegas e do Mestre.

A segunda subcategoria com maior incidência de relatos (seis dos nove entrevistados) foi a de que o RPG promove a interação social, na qual os círculos de amizades adquiridos por meio do jogo são indicados pelos entrevistados como sendo um dos seus benefícios. Como já mencionado anteriormente, a temática da amizade é constante em toda a entrevista, mas essa amizade parece ser trabalhada e cristalizada dentro do próprio grupo onde o jogador se insere. O grupo se apresenta com forte coesão interna, mas, quando comparado ao restante da sociedade, torna-se isolado, e o que é apontado como benefício pode ser, na verdade, um agravante.

Outra sub-categoria apontada foi a diminuição da timidez, na qual a prática do RPG levaria a um comportamento mais desinibido por parte dos jogadores. Essa afirmação encontra o mesmo problema da categoria anterior, pois a espontaneidade desenvolvida pelo jogador muitas vezes se limita ao grupo de pertença, ou a outros grupos de RPG, sem se expandir para o restante da sociedade. Em relação à função de catarse, temos o RPG como forma de sair da realidade e de aliviar o stress do mundo real ao pôr as emoções no jogo. No depoimento de uma das entrevistadas, as lutas dentro do jogo do RPG permitiam aliviar a tensão que tinha em decorrência de conflitos familiares. O restante das subcategorias são: prevenção contra drogas, pois a maior parte dos jogadores de RPG não teria hábitos que envolvessem bebida ou uso de outros tipos de drogas; incentivo à aquisição de novas línguas, já que, por possuir muito material em outras línguas e que não foram publicados no Brasil, os jogadores acabam por entrar em contato com outros idiomas; vivenciar diferentes experiências, através da possibilidade de simular diferentes situações e de aprender a se colocar no lugar de outras pessoas; contato com outras formas de cultura, devido ao fato de as temáticas propostas pelos jogos levarem os jogadores a buscar outras fontes de informação: livros de história, geografia, revistas, desenhos animados, etc; incentivo à 
leitura, porque alguns manuais de regras possuem mais de trezentas páginas e propõem outras leituras complementares para o jogo, o que incentivaria a prática da leitura entre os participantes; estimula a imaginação e a criatividade, sendo estas duas últimas o resultado da interpretação dinâmica no momento de jogo, quando é preciso imaginar os cenários descritos pelo Mestre e resolver as situações-problema propostas por ele.

Dentre as subcategorias citadas nos aspectos positivos, aumento de raciocínio, incentivo à aquisição de novos idiomas, vivenciar diferentes experiências, contato com outras formas de cultura, incentivo a leitura e estímulo a imaginação e a criatividade vão encontrar apoio no campo da pedagogia, no qual o RPG é usado na sala de aula (Klimick \& Bettocchi, 2003; Rodrigues, 2004; Silveira, n.d.). As subcategorias incentivo à leitura, estímulo à imaginação e estímulo à criatividade encontram respaldo na teoria de Rodriguez (2004) no uso do RPG para promover a pedagogia da imaginação de Ítalo Calvino. Este último acreditava que, no mundo moderno em que vivemos, somos bombardeados diariamente por imagens pré-fabricadas, por uma massificação visual, que empobrece o nosso potencial imaginativo, ressaltando a importância de se trabalhar com a pedagogia da imaginação, ou seja, com a releitura e a reconstrução dessas imagens, tanto visuais como literárias, dando-lhes uma nova forma. O RPG serviria como ferramenta para criar o espaço necessário onde essa prática se desenvolveria.

A categoria aspectos negativos é composta por cinco subcategorias: vício em RPG, sedentarismo, tolerância à agressividade, incentivo à agressividade e restrição ao círculo de RPG. Exemplos das evocações são apresentadas na Tabela 3:

Tabela 3. Dados referentes à categoria aspectos negativos do RPG.

\section{Subcategoria Exemplos das Evocações}

"Eu jogava muito, eu jogava... se eu passasse três dias sem jogar, eu ficava doente" (entrevistado 01).

“... É tipo um ópio, você esquece o mundo real e vai pro mundo imaginário. Você foge um pouco dos seus problemas, das suas raivas" (entrevistado 01).

"...Existem pessoas que deixam de viver um pouco os outros aspectos da vida, e colocam o RPG como se aquilo fosse o sentido da vida delas" (entrevistado 02).

Vício em RPG da realidade" (entrevistado 06).

"O que eu acho ruim é isso, de quem se bitola e que... se realiza somente no virtual" (entrevistado 06).

"O tempo perdido! Demora muito! Tem gente que vicia" (entrevistado 09).

“...Mas a maioria das pessoas que jogam RPG, que são viciados mesmo, não têm atividade física" (entrevistado 01).

“...São poucos assim, eu diria, 20\% dos que estão viciados que fazem atividade

Sedentarismo física..." (entrevistado 01).

"A perda de tempo! A perda, não, o dispêndio de tempo em alguma coisa" (entrevistado 03). 
"Se você passa muito tempo jogando RPG, você acaba deixando de estudar, acaba deixando de namorar, acaba deixando de fazer outras coisas que seriam

Sedentarismo interessantes durante nossa formação em toda a vida" (entrevistado 03).

"Bom, você fica preso no fim de semana sem ir pra uma boite só pra jogar, num acho vantagem, mas só isso" (entrevistado 07).

“...A gente acaba imbuindo valores agressivos no nosso próprio cotidiano, a gente fica mais insensivel" (entrevistado 03).

Tolerância à

agressividade

"Porque você acaba se familiarizando com o ambiente violento, de bater, de matar, de arrancar cabeça..." (entrevistado 03).

"Além dessa insensibilização, é um incentivo à agressão. Não sei se você

Incentivo à

agressividade percebe, mas todo jogador de RPG tem uma linguagem muito agressiva, não é questão de palavrões, é uma coisa agressiva, mesmo, sabe? Eles não têm tanta diplomacia quanto poderiam" (entrevistado 03).

"Então eu acho que isso dificulta fazer círculos de amizades com outros tipos de pessoas que não são jogadores de RPG, ou afins..." (entrevistado 03).

Restrição ao círculo de RPG
"Mas em um período que eu poderia estar tendo contato com outras pessoas que eram da minha sala, eu não tinha, ficava só com a galera do RPG" (entrevistado 03).

A primeira delas, e a mais mencionada nas entrevistas, fala sobre o vício no jogo de RPG, na dependência que pode vir a surgir, segundo os entrevistados, da fuga em excesso da realidade, em que o jogo proporcionaria uma estimulação semelhante à de outros entorpecentes e faria esquecer os problemas cotidianos. O vício em jogos já foi constatado em pesquisas estrangeiras, que afirmam que a dependência dos jogadores é exatamente igual à provocada por outras drogas (Games, 2003), e, apesar de esses estudos se referirem a jogos eletrônicos, não deve ser descartada a possibilidade de que esses mesmos efeitos ocorram em jogos de tabuleiro.

Outro problema conseqüente do jogo foi indicado como o sedentarismo causado por sua prática, uma vez que esses jogadores dedicariam muito tempo ao RPG e acabariam por não se interessar por outros tipos de atividade. Essa subcategoria está muito relacionada com a do vício, já que, quanto maior for a dependência no jogo, provavelmente menor será o tempo dedicado em outras atividades. As subcategorias tolerância à agressividade e incentivo à agressividade chamam a atenção para a característica violenta do jogo, que tem, em sua estrutura básica, regras de combate. Essas regras são um grande atrativo no RPG, e as batalhas em jogo são freqüentes, o que, segundo o entrevistado, acabaria por estimular esse tipo de conduta na vida dos jogadores, além de aumentar a tolerância à agressividade dos mesmos. A última das subcategorias dos aspectos negativos é a restrição ao círculo de RPG, que chama a atenção para um problema já mencionado anteriormente, no qual os jogadores ficam limitados aos laços estabelecidos dentro do grupo de RPG, o que dificultaria o ingresso em outros grupos sociais que não estivessem envolvidos com o jogo.

Há uma diferença considerável entre o número de aspectos negativos e de positivos evocados pelos entrevistados. Alguns participantes sequer apontaram tais aspectos, e nenhum deles conseguiu citar os cinco pontos negativos propostos pela entrevista. Na verdade, três das cinco categorias 
(tolerância à agressividade, incentivo à agressividade e restrição ao círculo de RPG) foram postas por apenas um dos jogadores, sendo que a última foi corroborada pelo relato de outros participantes no decorrer da entrevista. Outro ponto interessante é que, quando solicitados a falar sobre o que o RPG traz ou trouxe de ruim para a sua vida, as respostas eram dadas em relação aos outros, e os participantes dificilmente mencionavam a si próprios no depoimento, ao contrário do que acontecia quando os pontos eram positivos.

Devido às notícias vinculadas pela mídia, de assassinatos decorrentes da prática do jogo de RPG (Jogo Macrabo, 2005; Lopes, 2003), alguns participantes se posicionaram em uma postura defensiva ao jogo. Essa postura manifestou-se de forma natural, não sendo nenhuma das perguntas da entrevista dirigidas a essa temática, conforme descrito na Tabela 4.

Tabela 4. Relatos de defesa ao jogo de RPG.

Categoria Exemplos das Evocações

"...Agora, isso é porque a pessoa, ela já era desestruturada, aí começou a jogar RPG, aí gostou. RPG é uma coisa agradável, aí... fez daquilo ali o dia a dia dela..." (entrevistado 02).

"Pra mim, antigamente, eu via o RPG exatamente como as pessoas vê hoje em dia e que não tem conhecimento, como um jogo de doido..." (entrevistado 04).

"Eu fui apresentado de forma correta ao RPG. Então eu comecei a entender e ver que aquilo não tinha tanto a loucura que todo mundo tem o preconceito de colocar" (entrevistado 04).

Defesa ao RPG

"Você se torna mais compreensível, porque, por exemplo, quando sai uma notícia no jornal dizendo que jogadores de RPG mataram pessoas e as pessoas dizem que RPG é coisa de psicopata, você sabe que não é assim, e até sabe defender sua opinião" (entrevistado 06).

"(risos) Tem uma comunidade que fala assim: 'jogo RPG e não sou assassino'... Tipo, pra pessoas que não conhecem, antes de julgar tem que saber o que é" (entrevistado 07).

“...O ponto ruim é a visão que o RPG passa às pessoas leigas, o que é normal, pois, em alguns grupos de RPG, as pessoas usam velas, simulam algumas ações, rituais, cantos... que podem ser mal interpretados pelas pessoas..." (entrevistado 08).

"A mãe de um dos nossos jogadores, que é fanática religiosa, já comentou que isso é 'jogo do diabo', mas, vendo o jogo, viu que era apenas um faz de contas..." (entrevistado 08).

\section{Considerações finais}

Os jogos de RPG parecem ser compostos por elementos que variam em diferentes níveis de funcionalidade. Ao que tudo indica, tais níveis variam desde uma suposta melhora na aquisição de conhecimentos e formação de grupos sociais, passando por meros comportamentos lúdicos e, em alguns casos, assumindo a forma de viciação dos jogos de azar. Se for usado de forma apropriada, 
pode se tornar uma ferramenta de auxílio ao ensino, área em que já vem sendo aplicado por alguns educadores (Fortuna, 2001; Pavão, 1999; Rodrigues, 2004; Silveira, n.d.). Mas se, ao contrário, for empregado de maneira inadequada, pode resultar em problemas que vão desde o vício ao confinamento em grupos específicos limitados a relacionamentos intragrupais.

A amizade foi tema central de quase todas as entrevistas, sendo considerada desde o contato inicial com o jogo até a motivação atual dos jogadores. Esse princípio unificante do grupo de jogadores pode ser um caminho que leve a novas maneiras de se desenvolver interações em grupos escolares e, quem sabe, possa até prover métodos alternativos de terapia em grupo, complementando as técnicas já existentes de interpretação de papéis na clínica.

Devido à natureza deste estudo, não nos foi permitido, e nem era o objetivo desde trabalho, realizar uma análise estatística mais aprofundada sobre os dados obtidos. As categorias que emergiram durante a análise dos dados servem, além de descreverem as características e crenças dos jogadores, para apontar as próximas metas que certamente serão avaliados em pesquisas posteriores. Como exemplos de tais metas, estão a verificação de correlações entre as crenças evocadas durante as entrevistas e a conduta dos jogadores, bem como a aplicação de inventários que permitam melhor descrição da sua personalidade.

O principal benefício trazido por esta pesquisa foi justamente o de explorar e abrir as portas para outros estudos que poderão ser realizados mediante as informações coletadas. Ao que tudo indica, ainda há muito a se aprender sobre esse curioso jogo, que ganha cada vez mais espaço no campo da pedagogia e na prática de tantos jovens que vivem imersos em uma era de tecnologia que sufoca cada vez mais seu potencial criativo. É preciso se apropriar da cultura em massa que emerge em nossa sociedade sem se deixar intimidar pelo bombardeio de informações a que estamos submetidos atualmente, e fazer uso de tais informações a favor da educação. A Psicologia pode ser um meio essencial para se fazer uma leitura apropriada do RPG e para se explorar suas propriedades, sejam elas de natureza prejudicial ou edificante para a educação ou para o desenvolvimento do conhecimento. 


\section{Ana Alayde Saldanha*}

Doutora em Psicologia pela FFCLRP/USP, professora do Programa de Pós-Graduação em Psicologia Social da Universidade Federal da Paraíba, João Pessoa, PB - Brasil.

E-mail: analayde@terra.com.br

\section{José Roniere Morais Batista}

Graduado em Psicologia pela Universidade Federal da Paraíba, João Pessoa, PB - Brasil.

E-mail: roniere@gmail.com

*Endereço para envio de correspondência:

Av. Pres. Epitácio Pessoa, 4776, apt 601 - Cabo Branco, João Pessoa, PB - Brasil - CEP: 58045-000

Recebido 26/07/2008, Reformulado 26/01/2009, Aprovado 02/02/2009 


\section{Referências}

Cook, M., Twet, J., \& Williams, S. (2004). Dungeons e dragons: livro do jogador: livro de regras básicas V.3.5. São Paulo: Devir.

Figueiredo, M.A.C. (1993). Profissionais de saúde e aids. Um estudo diferencial. Medicina, 26(3), 393-407.

Fortuna, T. R. (2001). Formando professores na universidade para brincar. In S. M. P. Santos, A ludicidade como ciência. Petrópolis, RJ: Vozes.

Games viciam, assim como outras drogas, dizem cientistas. (2003). Recuperado em 27 de fevereiro de 2007, da Folha Online: http://www1.folha.uol.com.br/folha/informatica/ ult124u14376.shtml

Huizinga, J. (1996). Homo ludens. São Paulo: Perspectiva.

Ivanov, C. (2005). Two fanatic world of warcraft gamers have died because of WoW - Are there more to come? Recuperado em 28 de fevereiro de 2007, da Softpedia [On line]: http:// news.softpedia.com/news/Two-Fanatic-World-of-WarctaftGamers-Have-Died-Becouse-Of-WoW-11821.shtml

Jackson, S. (1994). GURPS: generic universal role-playing system: módulo básico. São Paulo: Devir.

Jogo Macabro. (2005). Recuperado em 25 de fevereiro de 2007, da Istoé Online: http://www.terra.com.br/istoe/1858/ brasil/1858_jogo_macabro.htm
Klimick, C., \& Bettocchi, E. (2003). O lugar do virtual no RPG, o lugar do RPG no design. Trabalho apresentado no II Simpósio do LaRS: Atopia, Departamento de Artes e Design, PUC-Rio, Rio de Janeiro.

Lopes, R. J. (2003). Violência, jogo e vida real. Recuperado em 25 de fevereiro de 2007, da Folha Online: http://www1.folha. uol.com.br/folha/sinapse/ult1063u470.shtml

Pavão, A. (1999). Aventura da leitura e da escrita entre mestres de role playing games $(R P G)$. Rio de Janeiro: EntreLugar.

Rodrigues, S. (2004). Roleplayng game: e a pedagogia da imaginação no Brasil. Rio de Janeiro: Bertrand Brasil.

Silveira, F. S. (n.d.). RPG na sala de aula: criando um ambiente lúdico para o ensino da língua inglesa. Recuperado em 25 de fevereiro de 2007, de http://www.rpgeduc.com/artigo01.pdf

Simões, V. L. (2000). Histórias infantis e aquisição de escrita. São Paulo em Perspectiva, 14(1), 22-28.

Winter, S. (1999). Livro do jogador: advanced dungeons e dragons. São Paulo: Devir. 